\section{The
Journal of
Health Design}

EDITORIAL

\title{
Widening the lens: Clinical
}

\section{perspectives on design thinking for public health}

\author{
Benjamin S Bassin 1 , Bella Nagappan'1, Cemal B Sozener ${ }^{1}$, Shalini S \\ Kota ${ }^{2}$, Diana C Anderson ${ }^{3}$
}

1. Department of Emergency Medicine, Division of Critical Care, University of Michigan Health System/Michigan Medicine

2. University of Toledo College of Medicine and Life Sciences, Toledo, OH, US

3. Division of Geriatrics, University of California-San Francisco, San Francisco, CA, US

To Cite: Bassin BS, Nagappan B, Sozener CB, Kota SS, Anderson DC. Widening the lens: Clinical perspectives on design thinking for public health. JHD. 2020;5(3):323-328.

https://doi.org/10.21853/JHD.2020.118

Corresponding Author:

Benjamin S. Bassin, MD

1500 East Medical Center Drive

B1354D Taubman Center

Ann Arbor, Ml 48109

bsbassin@med.umich.edu

(C2020 The Authors. Published by

Archetype Health Pty Ltd. This is an open

access article under the

CC BY-NC-ND 4.0 license.

\begin{abstract}
SUMMARY
Design thinking is a low-cost, high-value process that lends perspective to public health issues, generates innovative solutions, and challenges our current understanding of the world around us. The COVID-19 pandemic has created many stressors and challenges across all levels of low to highly resourced health systems. However, it has also shown the incredible number of opportunities for innovation, ingenuity, and system reengineering. It is time for a paradigm change and health care's next big investment: intentional and embedded partnerships between clinicians, designers, and architects with dedicated resources to ensure an effective collaborative environment to help solve health care's greatest challenges.

\section{Key Words}

Architecture, design thinking, innovation, public health, COVID-19
\end{abstract}

Design thinking is a low-cost, high-value, problem-solving, research, and reframing process that has the potential to lend perspective to public health issues, generate innovative solutions, and challenge our current understanding of the world around us. It has been adapted from the engineering and architecture fields to use client participatory processes to facilitate innovation and problem-solving. Design thinking may apply to a process, physical space, concrete object, or policy and by virtue of its broad nature, brings together domain experts across disciplines. A trained designer will use observation, conventional and unconventional information-gathering strategies, and problem-reframing to gather and find meaning in latent and conscious knowledge. ${ }^{1}$

When a pandemic or public health crisis occurs, the healthcare delivery system is stressed and disrupted, further revealing latent design flaws, exaggerating disparities, and potentiating inefficiencies in the system. However, times of significant stress drive periods of great ingenuity. This shortfall in the healthcare delivery system highlights the need for efficient system design long before we enter crisis mode, but also opens the door for justin-time innovation to close the gap when latent system flaws are exposed. The media is ripe with examples of rapid innovation and design solutions to combat the supply chain and physical space stressors that COVID-19 has put on healthcare systems-from micro 
to macro-from 3D-printed face masks to homemade ventilators to the conversion of dormitories and athletic facilities into field hospitals..$^{2-4}$

Just-in-time innovations have the potential to be scaled, but deployment of innovations and even simple public health measures, such as social distancing, may be difficult in a limited-resource community or high-population density environment. Healthcare systems with limited resources may not have the robust supply chain or infrastructure to handle a surge in critically ill patients. ${ }^{4}$ Highly communicable diseases such as COVID19 are potentially devastating in this environment, placing high stakes on preventative public health measures. ${ }^{5}$ Could our most recent experience with this pandemic have gone differently if design thinking was involved in strategic community and healthcare planning? What if we planned for these types of innovations long before a pandemic occurred and forced our hand? Can health care begin addressing community and societal needs through architecture and design?

The provision of health care at the bedside is the final step in a long line of strategic decisions that are made far upstream of actual care delivery. Many of those decisions have critical design elements that encompass the built environment, key equipment, workflows, staff and patient movement, and safety and quality. When healthcare delivery decisions do not include strategic design thinking, the result can be a cascading and compounding effect of inefficiencies and missed opportunities.

Our present situation with COVID-19 demonstrates the dire need for embedded architects and designers within health care on the individual, population, and policy levels. Thoughtful proactive design solutions based on community-specific needs have the potential to drastically reduce disease transmission, many in ways that may not be apparent at first glance without a deep understanding of the root cause of the problem. Design research can also lead to positive impacts on some of the other most prevalent contagious infectious diseases internationally, including tuberculosis, waterborne diarrheal illness, and influenza. ${ }^{5}$

Current evidence-based healthcare design practices rely on empirical data to inform design decisions. However, once the challenge is understood, rapid upscaling of innovative design solutions can occur as well. As an example, in work previously reported in The International Journal of Tuberculosis and Lung Disease, the creation of portable negative pressure helmets and tents were shown to increase the array of medical interventions able to be used with COVID-19-positive patients, while protecting healthcare workers from virus exposure during aerosol-generating procedures when negative pressure treatment spaces were not available. ${ }^{6,7}$ Emphasis on just-in-time, interdisciplinary collaboration in design thinking led to a paradigm shift when addressing the challenge of healthcare environments with pervasive personal protective equipment 
(PPE) shortages. Collaborative design thinking culminated in innovations based on the restructured solution of augmenting PPE on patients instead of on providers. Innovations to contain viral transmission by focusing on patients for novel PPE design provides for tangible improvements to existing design in infection control. These include safety in even non-traditional healthcare environments as well as efficiency and flexibility, compared to the scarce resource of a negative pressure room.

The negative pressure helmet and tent use the same principles of air flow as the built environment of the negative pressure room, but are portable, and more efficient (provide more air exchanges per hour) at a fraction of the cost. These innovative solutions have the potential to increase access to negative pressure environments where existing design fails to provide adequate single-room care for dense populations. In acute care models, moving towards a single-room paradigm for patients is associated with a sustained decrease in the rates of new infection. ${ }^{8}$ These findings have important implications for the role of both individual and innovative design as well as building and facility design in promoting positive infection control and health outcomes.

Although design thinking in health care could theoretically enhance innovation, health outcomes and care delivery, the challenge remains in how best to integrate this approachone that prioritises developing empathy for users and working in collaborative multidisciplinary teams. ${ }^{9}$

A number of new and established programs around the world use design thinking in medicine and extend to public health. JeffDESIGN, based at Thomas Jefferson University in Philadelphia, Pennsylvania, and the Design Institute for Health at the Dell Medical School in Austin, Texas, teach medical students to apply design thinking to solve healthcare challenges. The Institute for Healthcare Delivery Design embedded within the University of Illinois Hospital is a design lab that has helped align goals across the institution and facilitate research endeavours in service to the local community. The OpenLab, located in Toronto at Canada's research hospital-the University Health Network-is a design and innovation program that leads creative projects to improve healthcare experience and service delivery. The Better Lab, a research centre under the auspices of the University of California at San Francisco (UCSF), located at the Zuckerberg San Francisco General (ZSFG) Hospital, is a venture that uses human-centred design to study and fix healthcare challenges. Another approach can be found at the Centre for Excellence in Universal Design (CEUD), a design-led initiative based in Dublin, Ireland. CEUD focuses on environments that can be accessed, understood, and used to the greatest extent possible by all users (irrespective of their age, size, ability, or disability). The centre collaborates with health professionals to develop built environment guidelines. 
Each program listed above serves a specific community and funding for such design centres may come from grants, donors, local academic institutions, or the local health system. The growing number of trained designers and design labs within health care is evidence of the increasing recognition and need for thoughtful, human-centred design through collaboration. To facilitate collaboration, we propose some changes to ensure a convergence of these disciplines:

1. Hospitals and health systems should designate design thought leaders (designers with healthcare experience or masters-level training and/or physicians with design, Six Sigma, and/or LEAN training) and engage healthcare architects with knowledge of evidence-based design. These individuals possess a unique set of skills to mediate conversation between various disciplines, creatively assess the current-state, and reframe problems.

2. When a problem is identified, healthcare providers and designers should attempt to focus discussion around desired outcomes (eg, decreased crowding in waiting rooms to prevent spread of infection) rather than a specific solution (eg, larger waiting room). This allows the designer to research and propose targeted solutions that may be more cost-effective (eg, online waiting room and text notifications instructing when to enter the building).

3. From an educational perspective, we need to further integrate design teaching by building a hybrid model within medicine and public health programs. One example would be hosting Design Thinking workshops for continuing medical education (CME) credit.

4. Healthcare designers and architects should be trusted partners in emergency preparedness/public health discussions and planning to help find equitable, humancentred, and just solutions to healthcare challenges.

5. Design should be integrated into health care in a scalable continuum from micro to macro that spans from product design to facility and built environment design, in addition to delivery and systems of care design.

In summary, the COVID-19 pandemic has created many stressors and challenges across all levels of low to highly resourced health systems. However, it has also shown the incredible number of opportunities for innovation, ingenuity, and system reengineering. We think it is time to support a paradigm change and advocate for health care's next big investment: intentional and embedded partnerships between clinicians, designers, and architects with dedicated resources to ensure an effective collaborative environment to help solve health care's greatest challenges. 


\section{REFERENCES}

1. Sanders E, Stappers PJ. Convivial Design Toolbox: Generative Research for the Front End of Design., 2012. London: Laurence King Publishing.

2. Ford Media Center. Ford to Produce 50,000 Ventilators in Michigan in Next 100 Days; Partnering with GE Healthcare Will Help Coronavirus Patients. [2020 Mar 30]. [Accessed 2020 Jun 10]. Available from: https://media.ford.com/content/fordmedia/fna/us/en/news/2020/03/30/fordto-produce-50-000-ventilators-in-michigan-in-next-100-days.html

3. Ranney ML, Griffeth V, Jha AK. Critical Supply Shortages-The Need for Ventilators and Personal Protective Equipment during the Covid-19 Pandemic. N Engl J Med. 2020; 382:e41. DOI: 10.1056/NEJMp2006141

4. Waldstein D. With Games Paused, Sports Companies Shift to Making Medical Supplies. The New York Times [2020 Apr 7]. [Accessed 2020 Jun 10]. Available from: https://www.nytimes.com/2020/04/07/sports/formula-one-bauer-coronavirusppe.html

5. Akbar R. Ten Threats to Global Health in 2019. World Health Organization. [Accessed 2020 Jun 10]. Available from: https://www.who.int/newsroom/spotlight/ten-threats-to-global-health-in-2019

6. Bassin BS, Haas NL, Puls A, et al. Rapid development of a portable negative pressure procedural tent. International Journal of Tuberculosis and Lung Disease. 2020 Jul 1;24(7):740-3. DOI: $10.5588 /$ ijtld.20.0317

7. Haas NL, Bassin BS, Kota S, et al. Rapid development of a novel portable negative pressure device. International Journal of Tuberculosis and Lung Disease. 2020 Jul 1;27(7):737-9. DOI: $10.5588 /$ ijtld.20.0282

8. McDonald EG, Dendukuri N, Frenette C., et al. Time-Series Analysis of Health CareAssociated Infections in a New Hospital with All Private Rooms. JAMA Intern Med. 2019;179(11):1501-6. DOI: 10.1001/jamainternmed.2019.2798

9. Hamington M. Integrating Care Ethics and Design Thinking. J Bus Ethics. 2019; 155:91-103.

\section{ACKNOWLEDGEMENTS}

None

\section{PEER REVIEW}

Not commissioned. Externally peer reviewed.

\section{CONFLICTS OF INTEREST}

BS Bassin and SS Kota have submitted intellectual property claims on the negative pressure procedure helmet and tent briefly mentioned in this editorial and previously published in International Journal of Tuberculosis and Lung Disease. No other authors have any conflicts of interest to disclose. 
The
Journal of JHD 2020:5(3):323-328
Health Design

EDITORIAL

FUNDING

None

ETHICS COMMITTEE APPROVAL

None 